\title{
Facile Synthesis, Characterization and Antimicrobial Activities of Novel 6-Amino triazolo-thiadiazoles Integrated with Benzofuran and Pyrazole Moieties
}

\author{
MOHAMMAD IDREES, ${ }^{1 *}$ SATISH S. KOLA ${ }^{2}$ and NAQUI J. SIDDIQUI ${ }^{3}$ \\ 1,2Department of Chemistry, Institute of Science, Nagpur (M.S.), India. \\ ${ }^{3}$ Department of Chemistry, Government Science College, Gadchiroli (M.S.), India. \\ ${ }^{*}$ Corresponding author E-mail: idreesshaikh.2009@gmail.com
}

http://dx.doi.org/10.13005/ojc/350612

(Received: October 07, 2019; Accepted: December 05, 2019)

\begin{abstract}
In the present research we have reported simple efficient synthesis technique to afford a novel series of 3-(5-(benzofuran-2-yl)-1-phenyl-1H-pyrazol-3-yl)- $N$-aryl-[1,2,4]triazolo[3,4-b][1,3,4] thiadiazol-6-amine (4a-g) derivatives obtained by one pot cyclocondensation reaction of 5-(5(benzofuran-2-yl)-1-phenyl-1 H-pyrazol-3-yl)-4-amino-4H-1,2,4-triazole-3-thiol (3) with substituted aryl isothiocyanate in DMF and $\mathrm{K}_{2} \mathrm{CO}_{3}$, without formation undesirable side products by simple work up procedure. The structures yielded (4a-g) were established by ${ }^{13} \mathrm{CNMR}, \mathrm{IR},{ }^{1} \mathrm{HNMR}$, elemental analysis and mass spectra. Entire synthesised compounds were screened for their In vitro biological assay via microorganism Gram-positive and Gram-negative bacterial strains at different concentrations. The bioassay revealed that some of the compounds have promising antimicrobial activities when compared with standard drug Chloramphenicol.
\end{abstract}

Keywords: Triazolothiadiazole, Pyrazole, Benzofuran-2-yl, Antimicrobial.

\section{INTRODUCTION}

In recent years, fused heterocycles with three hetero atoms in five membered aromatic structures such as 1,2,4-triazoles and thiadiazoles sizable devotion owing to synthetic and remarkable pharmacological activities. The amino triazolothiadiazole system considered as a cyclic crucial and versatile fused five membered heterocycle ring structure incorporating two nitrogen and one sulphur atom. The numbers of triazoles fused to thiadiazoles exhibit various therapeutically important property probably due to the existence of N-C-S fragment in ring. Literature survey has revealed that the 6-amino thiadiazole structure plays vital role in biologically active compounds consequently represents fascinating moiety for therapeutic chemistry.1,3,4thiadiazoles are vital classes of azoles with significant pharmacological activities such antimicrobial ${ }^{1-6}$, antioxidant $^{7}$, antituberculosis ${ }^{8}$, anticancer ${ }^{9-11}$, analgesic $^{12}$, anti-inflammatory ${ }^{13}$, antiviral ${ }^{14-15}$, antifungal ${ }^{16-19}$, antitumor ${ }^{20}$, urease inhibitor ${ }^{21}$, analgesic and anti-inflammatory ${ }^{22}$, antidepressant ${ }^{23}$, anticonvulsant ${ }^{24}$, antimycotic ${ }^{25}$, diuretic ${ }^{26}$, cytotoxic ${ }^{27}$, corrosion inhibition effect ${ }^{28}$, antiproliferative ${ }^{29}$, anthelmintic ${ }^{30}$. Moreover, nowadays researchers

This is an Open Access article licensed under a Creative Commons license: Attribution 4.0 International (CC- BY). Published by Oriental Scientific Publishing Company @ 2018 
desire to yield fused or hybrids of various heteroatom ring to improve the medicinal property.

Prompted by these interpretations and in extension of our of determinations towards the synthesis of novel heterocyclic combinations with potent antimicrobial properties, in the present research we planned to frame a molecule and to synthesize and characterize a new series of condensed systems which combines two bio labile rings give a condensed and planar system of triazolothiadiazole with an anticipation to obtain compounds with better enhanced pharmacological activities and further thought of carrying out the antimicrobial studies of these innovative synthesized compounds against some bacterial strains.

\section{MATERIAL AND METHODS}

E. Merck TLC aluminium sheet silica gel was used for monitoring reactions; iodine and UV light chamber were utilized for visualizing of spots. Melting points obtained in open capillary tube. Shimadzu IR Spectrophotometer is used to record IR on a $\left(\mathrm{KBr}, v\right.$ max in $\left.\mathrm{cm}^{-1}\right)$. ESI mass spectra were noted on Waters Micromass Q-TOF Micro, Mass Spectrophotometer. ${ }^{1} \mathrm{H}$ NMR and ${ }^{13} \mathrm{CNMR}$ spectra are logged in Bruker AM instrument having $400 \mathrm{MHz}$ and values reported in (ppm) by $\left(\mathrm{CDCl}_{3}\right.$ and DMSOd6) in respect to tetramethylsilane (TMS). On Thermo Scientific (Flash-2000) element (CHN) analysis done using all the acquired products screened for their antimicrobial activities.

\section{General protocol to yield $3^{31}$}

Suspension of potassium salt (2) (20 $\mathrm{mmol}), 95 \%$ hydrazine hydrate $(40 \mathrm{mmol})$ in $\mathrm{H}_{2} \mathrm{O}$ (2 $\mathrm{mL}$ ) was taken in R.B flask and heated on condenser with occasional shaking for 1 hours. The colour of the content transformed to greenish with the evolution of $\mathrm{H}_{2} \mathrm{~S}$ gas. The resultant solution was added to ice cold water. The solid 3 was separated out by acidification with conc. $\mathrm{HCl}$, filtered, and recrystallization was carried out by using ethanol.

\section{Synthesis of 6-amino-1,2,4-triazolo[3,4-b][1,3,4] thiadiazole (4a-h)}

A mixture of compound $(3,3.74 \mathrm{~g}, 10 \mathrm{mmol})$, and 1-bromo-4-isothiocyanatobenzene $(2.14 \mathrm{~g}$, $10 \mathrm{mmol})$ in DMF $(25 \mathrm{~mL})$, was taken in round bottom flask to that potassium carbonate $(1.38 \mathrm{~g}, 10 \mathrm{mmol})$ was added then the reaction mixture was refluxed for 8 hours. Then reaction content was cooled discharged slowly with stirring into crush ice subsequent product obtained filtered, clean thoroughly with cold water. Correspondingly, $4 b-g$ were synthesised from 3 by extending the same method followed for $4 a$ and their structural identities were proved by chemical transformation reaction, physical data, and elemental analysis and IR spectra.

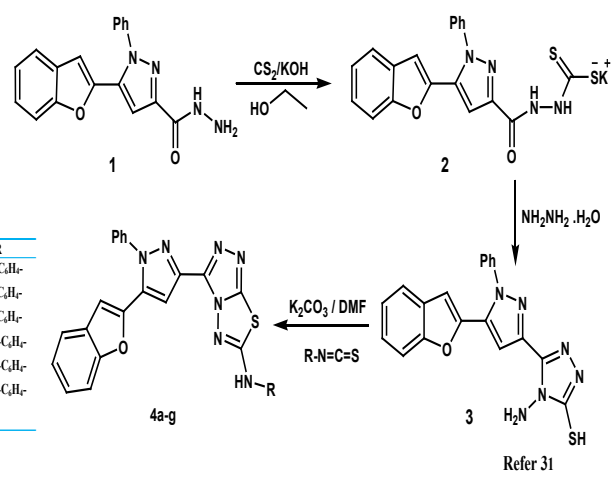

Reaction scheme. 1

\section{Spectral and Elemental analysis}

(4a): IR, 3440(N-H),1594,1636(N-H), 3079, 3020(CH ), 1497, 1518, 1594 (C=C), 1255(CO-C), 1636(C=N), 1255(C-N), 999(N-N), 749(C$\mathrm{S}-\mathrm{C}) \mathrm{cm}^{-1}$. ${ }^{1} \mathrm{H}$ NMR $\delta$ (ppm);14.86(s, $1 \mathrm{H}$, aromatic secondary $\mathrm{NH}$ group), 6.59 (s, $1 \mathrm{H}$, at $\mathrm{C} 4$ of pyrazole ring), 7.22-7.91 (m, 14H, aromatic + Heteroaryl proton). ${ }^{13} \mathrm{C}$ NMR (DMSO- $\left.d 6\right): \delta$ (ppm) 106, 111, 121, $123,125,127.41,129,135,136,138,144\left(s, 1 C, C_{3}\right.$ of pyrazole ring), $153\left(\mathrm{~s}, 1 \mathrm{C}, \mathrm{C}_{9}\right.$ of Benzofuran ring), $155,161\left(\mathrm{~s}, 1 \mathrm{C}, \mathrm{C}_{2}\right.$ of triazolothiadiazole), 171(s, 1C, $\mathrm{C}_{8}$ of triazolothiadiazoles).GC-MS (m/z): $556[\mathrm{M}+2]^{+}$. Elemental Analysis for $\mathrm{C}_{26} \mathrm{H}_{16} \mathrm{BrN}_{7} \mathrm{OS}$ Calculated, 56.33; H, 2.91; N, 17.68; S, 5.78 Found: C, 56.40; H, 2.98; N, 17.74; S, 5.70 .

(4b): IR, 3442(N-H), 1596, 1634(N-H), 3076, 3018(C-H), 1495, 1512, 1596(C=C), 1256(C-O-C), 1634(C=N), 1256( C-N), 1002(N-N), 750(C-S-C) cm-1.

(4c): IR, 3441(N-H), 1591, 1638(N-H), 3077, 3023(C-H), 1496, 1516, 1598(C=C), 1259 (C-O-C), 1634(C=N), 1259(C-N str.), 993(N-N), 742(C-S-C) cm-1.

(4d): IR, 3446(N-H), 3076, (C-H), 1497, 1594(C=C), 1257(C-O-C), 1638(C=N), 1257(C-N), 994(N-N), 748(C-S-C) $\mathrm{cm}^{-1}$.

(4e): IR, 3442(N-H), 3079, 3025(C-H.), 2995(C-H), 2918, 2810(C-H), 1494, 1516, 1593(C=C), 1254(C-O-C), 1630(C=N), $1254(\mathrm{C}-\mathrm{N})$, 995(N-N), 753(C-S-C) $\mathrm{cm}^{-1}$. 
(4f): IR, 3441(N-H), 3075, 3021(C-H), 1375(C-H), 1499, 1518,1593(C=C), 1256(C-O-C), 1078(C-O-C), 1632(C=N), 1256(C-N),996(N-N), 745(C-S-C) cm'.

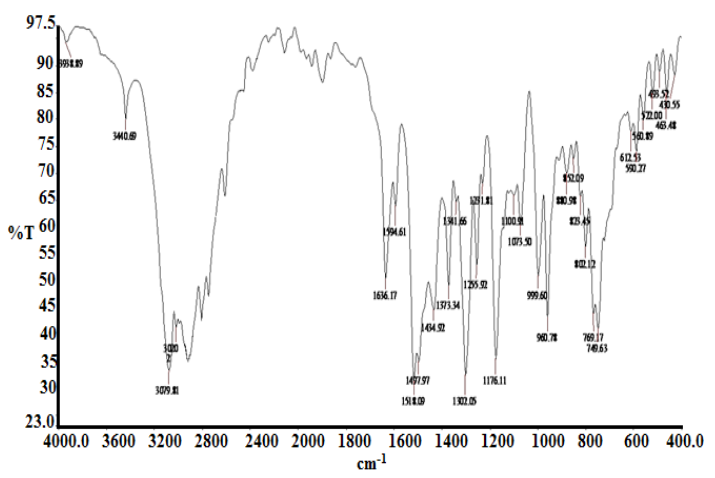

(4g): IR, 3447(N-H), 3078, 3023(C-H), 1498, 1513, $1592(\mathrm{C}=\mathrm{C} 1254(\mathrm{C}-\mathrm{O}-\mathrm{C}), 1634(\mathrm{C}=\mathrm{N})$, 1254(C-N str.), 994(N-N), 756(C-S-C) $\mathrm{cm}^{-1}$.

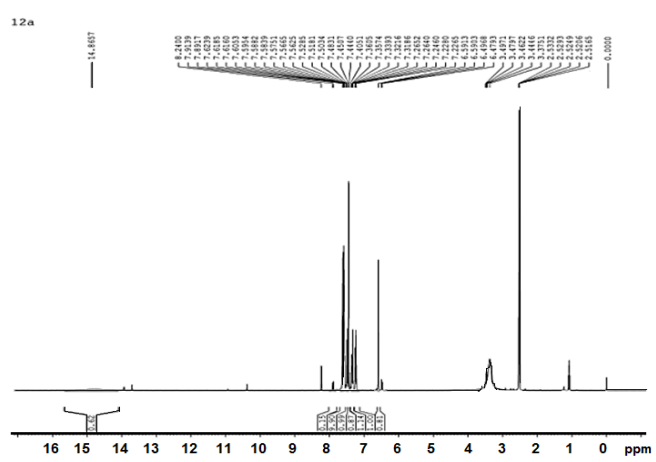

IR and ${ }^{1} \mathrm{H}$ NMR Spectra of $4 \mathrm{a}$
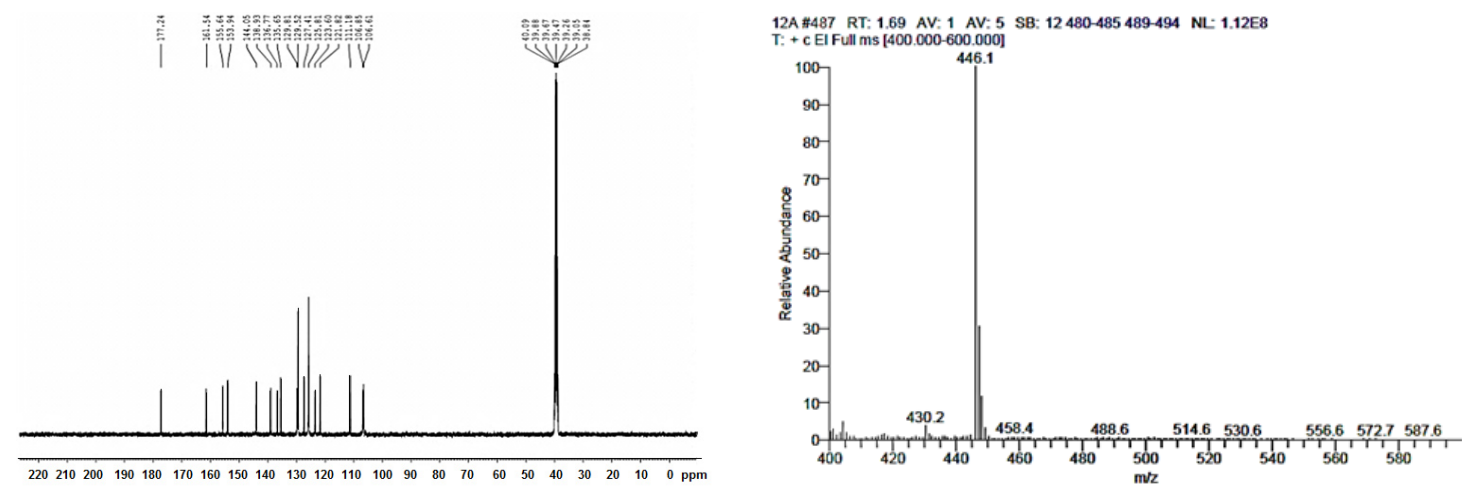

${ }^{13} \mathrm{C}$ NMR and Mass Spectra of $4 \mathrm{a}$

Antimicrobial Activities: Procedure (cup plate agar disc-diffusion method)

Solutions of tested compounds (4a-g) were prepared by dissolving calculated amount of every yielded product in DMSO to give final concentration of $31-1000 \mu \mathrm{g} / \mathrm{mL}$. Petri plates and agar solution are sterilized in autoclave. Petri plate is arranged by pouring agar solution. Bacterial culture was inoculated on fresh nutrient broth and further diluted with water $0.1 \mathrm{~mL}$ of diluted culture was banquet over nutrient agar in plate. Sterilized Whatmann paper circles $(6 \mathrm{~mm})$ were soaked in different tested compoundsand dried at room temperature then applied on petri plate and incubated at $37^{\circ} \mathrm{C}$ for $24 \mathrm{~h}$ zone of inhibition was measured in all direction in $\mathrm{mm}$ and taken as mean. Consequence was correlated with reference drug Chloramphenicol.

\section{RESULT AND DISCUSSION}

All novel synthesized compounds 4a-g has been corroborated by the spectroscopic examination such as FT-IR, ${ }^{1} \mathrm{HNMR}$, mass spectra and ${ }^{13} \mathrm{CNMR}$. For every final and intermediate product solubility and melting point was determined. The synthesis of target compound 6-amino triazolothiadiazole derivatives $4 \mathrm{a}-\mathrm{g}$ was carried out by cyclocondensation reaction of compound (3) with aryl isothiocyanate in DMF and potassium carbonate. The synthetic protocol has been outline in scheme1. The FT-IR result of compounds $4 \mathrm{a}-\mathrm{g}$, revealed the disappearance of absorption bands due to - $\mathrm{SH}$ and $-\mathrm{NH}_{2}$ stretching frequencies of initial compounds 3 and appearance of broad band at $3440 \mathrm{~cm}^{-1}$ for $\mathrm{NH}$ stretch. The new band which appeared at $1636 \mathrm{~cm}^{-1}$ region is recognized to stretching frequency of $\mathrm{C}=\mathrm{N}$ group of the thiadiazole ring further more absorption band at $749 \mathrm{~cm}^{-1}$ shows C-S-C stretch, undoubtedly indicated the cyclisation of compounds 3 and arylisothiocyanate in the presence of potassium carbonate to form triazolothiadiazole fused ring $4 a$. 
Table 1: Analytical and Physical data of 6-Amino Triazolothiadiazoles (4a-g)

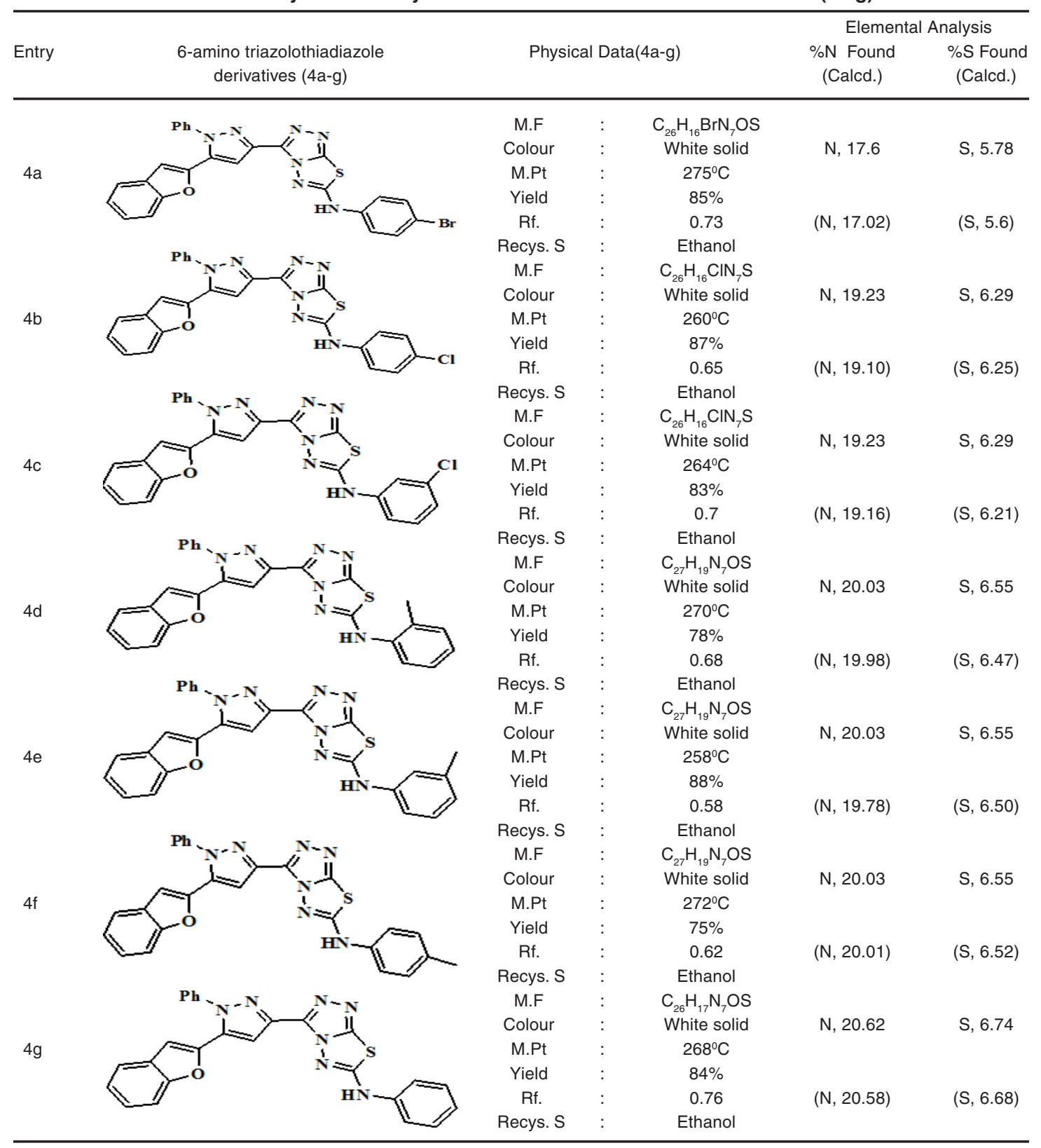

${ }^{1} \mathrm{HNMR}$ of $4 \mathrm{a}$ indicated disappearance of proton peak for $-\mathrm{SH}$ and $-\mathrm{NH}_{2}$ and occurrence of singlet at $\delta 14.56 \mathrm{ppm}$ shows the existence of aromatic secondary $\mathrm{NH}$ group, and another singlet at $\delta 6.59$ ppm shows existence of one proton at $\mathrm{C} 4$ of pyrazole ring. Apart from above signal rest of the signals were observed in the aromatic region. ${ }^{13} \mathrm{C}$ signals of $4 \mathrm{a}$ recorded a singlet at $\delta 161.54 \mathrm{ppm}$ due to and another signal at $\delta 171.2 \mathrm{ppm}$ due to $\mathrm{C} 8$ carbon of triazolothiadiazole that reveals expected cyclization, while other signals of ${ }^{13} \mathrm{CNMR}$ spectra of $4 \mathrm{a}$ were obtained at predicted chemical shifts values. Moreover the \% of $\mathrm{C}, \mathrm{H}, \mathrm{N}$ and $\mathrm{S}$ were establish to be $56.40,2.98,17.74,5.70$ respectively, which also indicates that it is in good conformity with molecular formulae $\mathrm{C}_{26} \mathrm{H}_{16} \mathrm{BrN}_{7} \mathrm{OS}$. Base peak in $\mathrm{GC}-\mathrm{MS}(\mathrm{m} / \mathrm{z})$ at $[\mathrm{M}+2]^{+}$at 556 also supported the formation of target compound. The nonappearance of characteristic absorption peaks due to $-\mathrm{NH}_{2}$ and $-\mathrm{SH}$ groups in $4 \mathrm{a}$ as earlier shown in 3 clearly 
confirmed its formation. The entire synthesized heterocyclic compounds 4a-g was assessed for their in-vitro antimicrobial activity. Results obtained are summarised in the Table No. 2 and 3.

Table 2: Antibacterial screening of (4a-i)

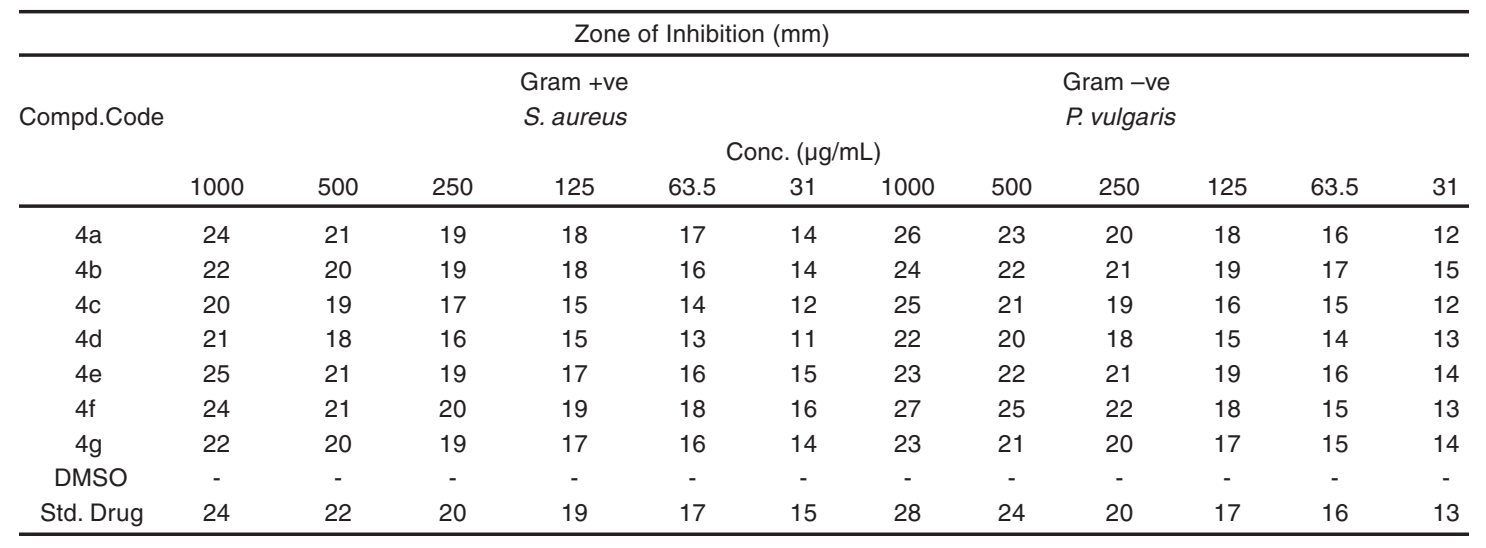

Table 3: Antibacterial screening of (4a-i)

\begin{tabular}{|c|c|c|c|c|c|c|c|c|c|c|c|c|}
\hline \multicolumn{13}{|c|}{ Zone of Inhibition (mm) } \\
\hline \multirow[t]{4}{*}{ Compd. Code } & \multicolumn{12}{|c|}{ Gram -ve } \\
\hline & \multicolumn{6}{|c|}{ E. coli } & \multicolumn{6}{|c|}{ S.typhi } \\
\hline & \multicolumn{12}{|c|}{ Conc. $(\mu \mathrm{g} / \mathrm{mL})$} \\
\hline & 1000 & 500 & 250 & 125 & 63.5 & 31 & 1000 & 500 & 250 & 125 & 63.5 & 31 \\
\hline $4 a$ & 26 & 24 & 22 & 19 & 17 & 15 & 16 & 15 & 13 & 10 & 09 & 07 \\
\hline $4 b$ & 23 & 21 & 20 & 18 & 16 & 14 & 14 & 12 & 11 & 09 & 08 & 06 \\
\hline $4 c$ & 24 & 22 & 19 & 17 & 15 & 13 & 15 & 13 & 10 & 08 & 07 & 05 \\
\hline $4 d$ & 26 & 23 & 22 & 20 & 18 & 15 & 12 & 10 & 09 & 07 & 06 & 04 \\
\hline $4 e$ & 25 & 24 & 21 & 18 & 17 & 14 & 15 & 14 & 12 & 11 & 09 & 07 \\
\hline $4 f$ & 24 & 23 & 20 & 17 & 16 & 13 & 13 & 12 & 10 & 08 & 07 & 05 \\
\hline $4 g$ & 20 & 19 & 17 & 16 & 14 & 12 & 14 & 13 & 11 & 10 & 08 & 06 \\
\hline DMSO & - & - & - & - & - & - & - & - & - & - & - & - \\
\hline Std. Drug & 26 & 24 & 23 & 21 & 17 & 14 & 17 & 15 & 12 & 11 & 09 & 08 \\
\hline
\end{tabular}

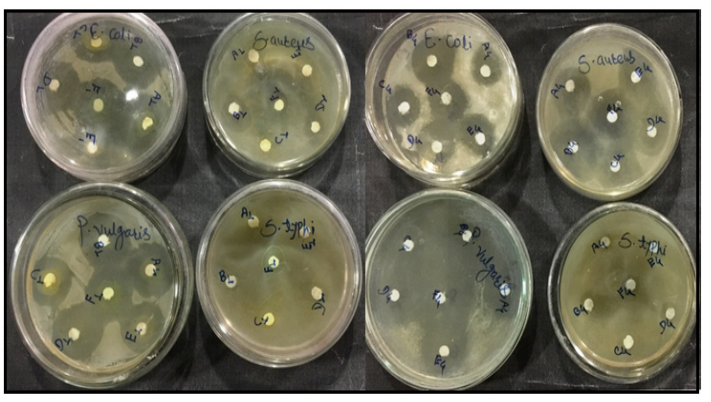

Fig. 1. Zone of Inhibition in $\mathrm{mm}$ for $4 \mathrm{a}$ and $4 \mathrm{e}$ at different conc. and bacterial strains

CONCLUSION

In conclusion, highly efficient and facile synthesis of novel series of 6 -amino thiadiazole (4a-g) derivatives is described. The presented series of compounds were synthesized in excellent yields without any additional reagents or catalyst. The structure and purity of innovative compounds obtained was established by spectroscopic study and chemical assessment. Among the synthesized compounds maximum compounds exhibited reasonable to good activities on selected strains $S$. aureus, E. coli and $P$. vulgaris while poor activity was assessed for S. typhi.

\section{ACKNOWLEDGEMENT}

The authors appreciate Dr. Roshan Nasare, Dr. Syed Abrar Ahmed and Dr. Mandar Paingankar, for their support and permission to carry out antimicrobial activities. Authors are also obliged to the Principal, Government Science College, Gadchiroli for providing laboratory conveniences. Authors are gratified to Director IIT Bombay and SAIF, Chandigarh for spectral analysis of compound.

\section{Conflict of interest}

The authors announce that there is no conflict of interest. 


\section{REFERENCES}

1. Tarik, E.; Mohammed, E.Eur. J. Chem., 2010, 1, 6-11.

2. Seelam, N.; Shrivastava, S.; Prasanthi, S.; Gupta, S. J. Saudi. Chem. Soc., 2016, 20, 411-418.

3. Singh, G.; Sharma, P.; Dadhwal, S.;Garg, P.; Sharma, S. Int. J. Curr. Pharm. Res., 2011, 3, 105-118.

4. Sheikhy, M.; Jalilian, A.; Novinrooz, A.; Motamedi-Sedeh, F. J. Biomed. Sci. Eng., 2012, 5, 39-42.

5. Singh, R.; Chouhan, A.World Pharma. Pharmace. Sci., 2014, 3, 874-906.

6. Kaushik, A.; Ganguly, S.; Sahu, J. K. J. Adv. Pharma. Tech. Res., 2014, 5(2), 90-95.

7. Hameed, A.; Hassan, F. Int. J. App. Sci. Tech., 2014, 4, 202-211.

8. Menendez, C.; Gau, S.; Lherbet, C.; Rodriguez, F.; Inard, C. Eur. J. Med. Chem., 2011, 46, 5524-5531.

9. Bekircan, O.; Kucuk, M.; Kahveci, B.; Kolayli, S. Arch. Pharm., 2005, 338, 365-372.

10. Sztanke, K.; Tuzimski, T.; Rzymowska, J.; Pasternak, K.; Kandefer-Szerszen, M. Eur. J. Med. Chem., 2008, 43, 404-419.

11. Baviskar, B. A.; Khadabadi, S. S.; Deore, S. L.; Shiradkar, M. R. Der. Pharmacia. Sinica., 2012, 3, 24-30.

12. Zitouni, G.; Kaplancikli, Z.A.; Erol, K.; Kilic, F. S. Farmaco., 1999, 54, 218-223.

13. Zitouni, G.T.; Kaplancikli, Z.A.; Ozdemir, A.; Chevallet, P.; Kandilci, H.B.; Gumus, B. Arch. Pharm., 2007, 340, 586-590.

14. Dong, W.; Liu, Z.; Liu, X.; Li, Z.; Zhao, W. Eur. J. Med.Chem., 2010, 45, 1919-1926.

15. Farghaly, A. R.; El-Kashef, H. Arkivoc., 2006, 11, 76-90.

16. Zou, Y.; Zhao, Q.; Liao, J.; Hu, H.; Shichong,
Y.; Chai, X.; Xu, M.; Qiuye, W. Bioorg. Med. Chem., 2012, 22, 2959-2962.

17. Uchil, V. R.; Joshi, V. Ind. J. Chem., 2002, 41, 631-634.

18. Shiv, K.; Gupta, P.K.; Sharma, M.; Bansal, Kumar, B. E. J. of Chem., 2011, 8(2), 594-597.

19. Li, Q.; Ren, J.; Dong, F.; Feng, Y.; Gu, G.; Guo, Z. Carbohydr. Res., 2013, 373, 103-107.

20. Bai, J. K.; Zhao, W.; Li, H. M.; Tang,Y. J. J. Tang. Curr. Med. Chem., 2012, 19, 927-936.

21. Khan, I.;Ali, S.;Hameed, S.; Rama, N.H.;Hussain, M. T. Eur. J. Med. Chem., 2010, 45, 5200-5207.

22. Salgin-Goksen, U.; Gokhan-Kelekci, N.; Goktas, O.; Koysal, Y.; Kilic, E. Bioorg. Med. Chem., 2007, 15, 5738-5751.

23. Yusuf, M.;Khan, A. R.; Ahmed, B. Bioorg. Med. Chem., 2008, 16(17), 8029-8034.

24. Sarafroz, M.; Khatoon, Y.; Ahmad, N.; Amir, M.; Pottoo, H. F. Orient. J. Chem., 2019, 35(1), 64-70.

25. Wujec, M.; Pitucha, M.; Dobosz, M.; Kosikowska, U.; Malm, A. Acta. Pharm., 2004, 54, 251-260.

26. Sanmati, K.; Mishra, P. J.Computational Method Mol. Des., 2011, 1(1), 52-58.

27. Karakus, S.; Coruh, U.; Barlas-Durgun, B.; Ezequiel, M.; Vazquez-Lopez, Ozbas-Turan, S.; Akbuga, J.; Rollas, S. Marmara. Pharm. J., 2010, 14, 84-90.

28. Joseph Raj, X.; Rjendran, N. Int. J. of Electrochemical Sci., 2011, 6, 348-366.

29. Matysiak, J. Eur. J. Med. Chem., 2007, 42, 940-947.

30. Bhusari, K. P.; Khedekar, P.B.; Umathe, S. N.;Bahekar, R. H.; Raghu Ram Rao, A. Ind. J. Hetero. Chem., 2000, 9(4),275-278.

31. Siddiqui, N.J.; Idrees M.; Khaty, N.T.; Dhonde, M.G.S., Am. J. Pharm. Tech. Res., 2015, 5(1), 290-300. 